Pacific Journal of Mathematics

GENERALIZATIONS OF THE ROGERS-RAMANUJAN 


\title{
GENERALIZATIONS OF THE ROGERS-RAMANUJAN IDENTITIES
}

\author{
HENRY L. ALDER
}

1. Introduction. The first of the two Rogers-Ramanujan identities [1, Chap. 19] states that

$$
\prod_{\nu=0}^{\infty} \frac{1}{\left(1-x^{5 \nu+1}\right)\left(1-x^{5 \nu+4}\right)}=\sum_{\mu=0}^{\infty} \frac{x^{\mu^{2}}}{(1-x)\left(1-x^{2}\right) \cdots\left(1-x^{\mu}\right)},
$$

where the left side is the generating function for the number of partitions into parts not congruent to $0, \pm 2(\bmod 5)$. This paper shows that as a generalization of (1) the generating function for the number of partitions into parts not congruent to $0, \pm k(\bmod 2 k+1)$, where $k$ is any positive integer, can be expressed as a sum similar to the one appearing in (1); in fact in general the $x^{\mu^{2}}$ are replaced by polynomials $G_{k, \mu}(x)$, so that we have the following the orem:

THEOREM 1. The following identity holds:

$$
\begin{gathered}
\prod_{\nu=0}^{\infty} \frac{\left(1-x^{(2 k+1) \nu+k}\right)\left(1-x^{(2 k+1) \nu+k+1}\right)}{\left(1-x^{(2 k+1) \nu+1}\right)\left(1-x^{(2 k+1) \nu+2}\right) \cdots\left(1-x^{(2 k+1) \nu+2 k}\right)} \\
=\sum_{\mu=0}^{\infty} \frac{G_{k, \mu}(x)}{(1-x)\left(1-x^{2}\right) \cdots\left(1-x^{\mu}\right)},
\end{gathered}
$$

where the left side is the generating function for the number of partitions into parts not congruent to $0, \pm k(\bmod 2 k+1)$. The $G_{k, \mu}(x)$ are polynomials in $x$ and reduce to the monomial $x^{\mu^{2}}$ for $k=2$, that is, for the Rogers-Ramanujan case.

While the right side of (1) is the generating function for the number of

Received March 12, 1953.

Pacific J. Math. 4 (1954), $161-168$ 
partitions into parts differing by at least 2, no similar interpretation of the right hand of (2) is possible. In particular, it follows from a theorem of the author [2] that the right side of (2) cannot be interpreted as the generating function for the number of partitions of $n$ into parts differing by at least $d$, each part being greater than or equal to $m$, unless $d=2, m=1$, that is, unless we have the Rogers-Ramanujan identity (1).

As a generalization of the second of the Rogers-Ramanujan identities:

$$
\prod_{\nu=0}^{\infty} \frac{1}{\left(1-x^{5 \nu+2}\right)\left(1-x^{5 \nu+3}\right)}=\sum_{\mu=0}^{\infty} \frac{x^{\mu^{2}+\mu}}{(1-x)\left(1-x^{2}\right) \cdots\left(1-x^{\mu}\right)},
$$

we have again that not only the generating function for the number of partitions into parts not congruent to $0, \pm 1(\bmod 5)$, but in general the one for the number of partitions into parts not congruent to $0, \pm 1(\bmod 2 k+1)$ can be expressed as a sum; in fact again the $x^{\mu^{2}}$ are replaced by the same polynomials $G_{k, \mu}(x)$ appearing in (2), so that we have the following theorem:

THEOREM 2. The following identity holds:

$$
\begin{aligned}
\prod_{\nu=0}^{\infty} \frac{1}{\left(1-x^{(2 k+1) \nu+2}\right)\left(1-x^{(2 k+1) \nu+3}\right)} & \ldots\left(1-x^{(2 k+1) \nu+2 k-1}\right) \\
& =\sum_{\mu=0}^{\infty} \frac{G_{k, \mu}(x) x^{\mu}}{(1-x)\left(1-x^{2}\right) \cdots\left(1-x^{\mu}\right)} .
\end{aligned}
$$

More generally, it can be shown that identities involving the generating function for the number of partitions into parts not congruent to $0, \pm(k-r)$ $(\bmod 2 k+1)$, where $0 \leq r \leq k-1$, can be obtained, of which $(2)$ is the particular case where $r=k-1$, that is, for each modulus $2 k+1$ there are $k$ identities.

2. Proof of Theorem 1: If we replace, in Jacobi's identity,

$$
\prod_{\nu=0}^{\infty}\left(1-y^{2 \nu+2}\right)\left[1+\left(z+z^{-1}\right) y^{2 \nu+1}+y^{4 \nu+2}\right]=\sum_{\mu=-\infty}^{\infty} y^{\mu^{2}} z^{\mu},
$$

$y$ by $x^{(2 k+1) / 2}$ and $z$ by $-x^{1 / 2}$, we have 
(6)

$$
\begin{array}{r}
\prod_{\nu=0}^{\infty}\left(1-x^{(2 k+1) \nu+k}\right)\left(1-x^{(2 k+1) \nu+k+1}\right)\left(1-x^{(2 k+1) \nu+(2 k+1)}\right) \\
\sum_{\mu=-\infty}^{\infty}(-1)^{\mu} x^{\left((2 k+1) \mu^{2}+\mu\right) / 2,}
\end{array}
$$

so that, dividing both sides of $(6)$ by $(1-x)\left(1-x^{2}\right)\left(1-x^{3}\right) \cdots$, we obtain

$$
\begin{gathered}
\prod_{\nu=0}^{\infty} \frac{\left(1-x^{(2 k+1) \nu+k}\right)\left(1-x^{(2 k+1) \nu+k+1}\right)}{\left(1-x^{(2 k+1) \nu+1}\right)\left(1-x^{(2 k+1) \nu+2}\right) \cdots\left(1-x^{(2 k+1) \nu+2 k}\right)} \\
=\frac{\sum_{\mu=-\infty}^{\infty}(-1)^{\mu} x^{\left((2 k+1) \mu^{2}+\mu\right) / 2}}{\prod_{s=1}^{\infty}\left(1-x^{s}\right)} .
\end{gathered}
$$

To prove Theorem 1, we therefore have to show that the right side of $(7)$ is the same as the right side of (2).

We use the auxiliary function

$$
\begin{aligned}
C_{k, i}(y)=1-y^{i} x^{i} & +\sum_{\mu=1}^{\infty}(-1)^{\mu} y^{k \mu} x^{(2 k+1)\left(\mu^{2}+\mu\right) / 2-i \mu} \\
\left(1-y^{i} x^{(2 \mu+1) i}\right) & \frac{(1-y x)\left(1-y x^{2}\right) \cdots\left(1-y x^{\mu}\right)}{(1-x)\left(1-x^{2}\right) \cdots\left(1-x^{\mu}\right)},
\end{aligned}
$$

which was first used by Selberg [3] and is a generalization of the function used in some proofs of the Rogers-Ramanujan identities [1, Chap. 19]. The function (8) converges if $|y|<1$ and if $k$ is real and $>-1 / 2$. In our case $k$ anu: will be nonnegative integers. For $i=k$ and $y=1,(8)$ reduces to

$$
C_{k, k}(1)=\sum_{\mu=-\infty}^{\infty}(-1)^{\mu} x\left((2 k+1) \mu^{2}+\mu\right) / 2 .
$$

Since the $C_{k, i}(y)$ satisfy the equation 


$$
C_{k, i}(y)=C_{k, i-1}(y)+y^{i-1} x^{i-1}(1-y x) C_{k, k-i+1}(y x)
$$

it is easily seen that we can find a functional equation for the $C_{k, k}(y)$, which can be found to be of the form

$$
C_{k, k}(y)=\sum_{\mu=1}^{k} A_{k, \mu}(y, x)\left(1-y x^{\mu}\right) C_{k, k}\left(y x^{\mu}\right) .
$$

If we let

$$
Q_{k}(y)=\frac{C_{k, k}(y)}{\prod_{s=1}^{\infty}\left(1-y x^{s}\right)},
$$

(10) reduces to

$$
Q_{k}(y)=\sum_{\mu=1}^{k} A_{k, \mu}(y, x) Q_{k}\left(y x^{\mu}\right) .
$$

If, for instance, $k=3,(12)$ becomes

$$
Q_{3}(y)=(1+y x) Q_{3}(y x)+y^{2} x^{2} Q_{3}\left(y x^{2}\right)-y^{3} x^{5} Q_{3}\left(y x^{3}\right),
$$

while for $k=4$ we would have

$$
\begin{aligned}
Q_{4}(y)=(1+y x) Q_{4}(y x)+y^{2} x^{2}(1 & \left.+y x+y x^{2}\right) Q_{4}\left(y x^{2}\right) \\
& -y^{4} x^{7} Q_{4}\left(y x^{3}\right)-y^{6} x^{13} Q_{4}\left(y x^{4}\right) .
\end{aligned}
$$

In order to solve (12) for $Q_{k}(y)$ we try a solution of the form

$$
Q_{k}(y)=\sum_{\mu=0}^{\infty} B_{k, \mu}(x) y^{\mu},
$$

where $B_{k, 0}(x)=Q_{k}(0)=1$ by use of $(11)$ and (8).

Putting (15) into (12) we obtain a difference equation for the $B_{k, \mu}(x)$. It can easily be verified that the $B_{k, \mu}(x)$ are of the form

$$
B_{k, \mu}(x)=\frac{G_{k, \mu}(x)}{(1-x)\left(1-x^{2}\right) \ldots\left(1-x^{\mu}\right)},
$$


where the $G_{k, \mu}(x)$ are polynomials in $x$ and reduce to the monomial $x^{\mu^{2}}$ for $k=2$. In general these polynomials do not seem to possess any striking properties, even for small values of $k$ and $\mu$, as shall be illustrated below for $k=3$ and $k=4$.

Substituting now (16) into (15), and remembering (11), we obtain

$$
Q_{k}(y)=\sum_{\mu=0}^{\infty} \frac{G_{k, \mu}(x) y^{\mu}}{(1-x)\left(1-x^{2}\right) \ldots\left(1-x^{\mu}\right)}=\frac{C_{k, k}(y)}{\prod_{s=1}^{\infty}\left(1-y x^{s}\right)},
$$

so that we have, in view of (9),

$$
\begin{aligned}
\frac{C_{k, k}(1)}{\prod_{s=1}^{\infty}\left(1-x^{s}\right)} & =\frac{\sum_{\mu=-\infty}^{\infty}(-1)^{\mu}\left((2 k+1) \mu^{2}+\mu\right) / 2}{\prod_{s=1}^{\infty}\left(1-x^{s}\right)} \\
& =\sum_{\mu=0}^{\infty} \frac{G_{k, \mu}(x)}{(1-x)\left(1-x^{2}\right) \ldots\left(1-x^{\mu}\right)},
\end{aligned}
$$

which completes the proof of the theorem.

In case $k=3$, the difference equation for the $B_{3, \mu}(x)$, which can easily be obtained from (13), is the following:

$$
B_{3, \mu}(x)\left(1-x^{\mu}\right)=B_{3, \mu-1}(x) x^{\mu}+B_{3, \mu-2}(x) x^{2 \mu-2}-B_{3, \mu-3}(x) x^{3 \mu-4},
$$

from which we calculate, remembering that $B_{3,0}(x)=1$ :

$$
\begin{aligned}
& G_{3,1}(x)=x, \\
& G_{3,2}(x)=x^{2}, \\
& G_{3,3}(x)=x^{5}+x^{6}-x^{8}, \\
& G_{3,4}(x)=x^{8}+x^{10}-x^{14}, \\
& G_{3,5}(x)=x^{13}+x^{14}+x^{15}-x^{18}-x^{19}, \\
& G_{3,6}(x)=x^{18}+x^{20}+x^{21}+x^{22}-x^{25}-x^{26}-x^{27}-x^{28}+x^{31}, \\
& G_{3,7}(x)=x^{25}+x^{26}+x^{27}+x^{28}+x^{29}-x^{32}-x^{33}-x^{34}-x^{35}-x^{36}+x^{42},
\end{aligned}
$$


and so on.

It can easily be verified by induction that the degree of the $G_{3, \mu}(x)$ is equal to

$$
\frac{5 \mu^{2}+\mu}{6} \text { if } \mu \equiv 0 \text { or } 1(\bmod 3)
$$

and is less than or equal to

$$
\frac{5 \mu^{2}-\mu-6}{6} \text { if } \mu \equiv 2 \quad(\bmod 3)
$$

Similarly, it can be shown that the term with smallest exponent in each polynomial $G_{3, \mu}(x)$ is $x^{\left[\left(\mu^{2}+1\right) / 2\right]}$, so that each polynomial has this power of $x$ as a divisor and no higher power.

For $k=4$, we obtain the difference equation for the $B_{4, \mu}(x)$ from (14):

$$
\begin{aligned}
B_{4, \mu}(x) & \left(1-x^{\mu}\right)=B_{4, \mu-1}(x) x^{\mu}+B_{4, \mu-2}(x) x^{2 \mu-2} \\
& +B_{4, \mu-3}(x) x^{2 \mu-3}(x+1)-B_{4, \mu-4}(x) x^{3 \mu-5}-B_{4, \mu-6}(x) x^{4 \mu-11},
\end{aligned}
$$

so that we obtain:

$G_{4,0}(x)=1$,

$G_{4,1}(x)=x$,

$G_{4,2}(x)=x^{2}$,

$G_{4,3}(x)=x^{3}$,

$G_{4,4}(x)=x^{6}+x^{7}+x^{8}-x^{9}-x^{10}-x^{11}+x^{13}$,

$G_{4,5}(x)=x^{9}+x^{10}+x^{11}-x^{14}-x^{15}-x^{16}+x^{20}$,

$G_{4,6}(x)=x^{12}+x^{14}+x^{15}+x^{16}-x^{19}-2 x^{20}-x^{21}-x^{22}+x^{25}+x^{26}$,

$G_{4,7}(x)=x^{17}+x^{18}+2 x^{19}+x^{20}+x^{21}-x^{23}-2 x^{24}-2 x^{25}-2 x^{26}-x^{27}+x^{30}$

$+x^{31}+x^{32}$ 
and so on.

In this case the term with smallest exponent can be shown to equal $x^{\left[\left(\mu^{2}+2\right) / 3\right]}$, while for $G_{5, \mu}(x)$ we would find the corresponding term to be $x^{\left[\left(\mu^{2}+3\right) / 4\right]^{9}}$ for $\mu>2$, and so on.

3. Proof of Theorem 2. From the definition of $C_{k, i}(y)$ we find

$$
(1-x) C_{k, k}(x)=\sum_{\mu=-\infty}^{\infty}(-1)^{\mu} x\left((2 k+1) \mu^{2}+(2 k-1) \mu\right) / 2 .
$$

Substituting now, in Jacobi's identity $(5), x^{(2 k+1) / 2}$ for $y$ and $-x^{(2 k-1) / 2}$ for $z$, and dividing at the same time both sides by $(1-x)\left(1-x^{2}\right)\left(1-x^{3}\right) \cdots$, we obtain

$$
\begin{aligned}
\prod_{\nu=0}^{\infty} & \frac{1}{\left(1-x^{(2 k+1) \nu+2}\right)\left(1-x^{(2 k+1) \nu+3}\right) \cdots\left(1-x^{(2 k+1) \nu+2 k-1}\right)} \\
& =\frac{\sum_{\mu=-\infty}^{\infty}(-1)^{\mu} x^{\left((2 k+1) \mu^{2}+(2 k-1) \mu\right) / 2}}{\prod_{s=1}^{\infty}\left(1-x^{s}\right)} \\
& =\frac{(1-x) C_{k, k}(x)}{\prod_{s=1}^{\infty}\left(1-x^{s}\right)}=Q_{k}(x)=\sum_{\mu=0}^{\infty} \frac{G_{k, \mu}(x) x^{\mu}}{(1-x)\left(1-x^{2}\right) \ldots\left(1-x^{\mu}\right)},
\end{aligned}
$$

if we recall (11), (15), and (16).

Identities involving the generating function for the number of partitions into parts not congruent to $0, \pm(k-r)(\bmod 2 k+1)$, where $0 \leq r \leq k-1$, can be obtained by noting that, using Jacobi's identity with $y=x^{(2 k+1) / 2}$ and $z=-x^{(2 r+1) / 2}$, we obtain

$$
\begin{array}{r}
\prod_{\nu=0}^{\infty}\left[\left(1-x^{(2 k+1) \nu+k-r}\right)\left(1-x^{(2 k+1) \nu+k+r+1}\right)\left(1-x^{(2 k+1) \nu+(2 k+1)}\right)\right] \\
=\sum_{\mu=-\infty}^{\infty}(-1)^{\mu} x^{\left((2 k+1) \mu^{2+(2 r+1) \mu) / 2},\right.}
\end{array}
$$


where the right side, as can be verified, is expressible in terms of $C_{k, k}(y)$, which was shown already for $r=0$ by Theorem 1 and for $r=k-1$ by Theorem 2 and shall only be indicated here for $r=1$, where we find

$$
\begin{aligned}
C_{k, k}(1)-x^{k-1}(1-x)\left(1-x^{2}\right) C_{k, k}\left(x^{2}\right) \\
=\sum_{\mu=-\infty}^{\infty}(-1)^{\mu} x^{\left((2 k+1) \mu^{2}+3 \mu\right) / 2} .
\end{aligned}
$$

This method therefore allows us to find for each modulus $2 k+1$ exactly $k$ identities, that is, one for each value of $r$ in $0 \leq r \leq k-1$.

\section{REFERENCES}

1. Hardy and Wright, Introduction to the theory of numbers, Oxford, 1938.

2. H. L. Alder, The nonexistence of certain identities in the theory of partitions and compositions, Bull. Amer. Math. Soc. 54 (1948), $712-722$.

3. A. Selberg, ̈̈ber einige arithmetische Identitäten, Norske Videnskaps-Akademi, Avhandlinger, 1936, 1-23 (No.8).

University of California, Davis 


\section{PACIFIC JOURNAL OF MATHEMATICS}

\section{EDITORS}

\author{
M.M. SCHIFFE R* \\ Stanford University \\ Stanford, California \\ E. HEWITT \\ University of Washington \\ Seattle 5, Washington
}

\author{
R.P. DILWORTH \\ Calif ornia Institute of Technology \\ Pasadena 4, California \\ E. F. BECKENBACH** \\ University of California \\ Los Angeles 24, California
}

\section{ASSOCIATE EDITORS}

$\begin{array}{llll}\text { H. BUSEMANN } & \text { P.R. HALMOS } & \text { BØRGE JESSEN } & \text { J. J. STOKER } \\ \text { HERBERT FEDERER } & \text { HEINZ HOPF } & \text { PAUL LÉVY } & \text { E. G. STRAUS } \\ \text { MARSHALL HALL } & \text { R.D. JAMES } & \text { GEORGE PÓLYA } & \text { KÔSAKU YOSIDA }\end{array}$

\section{SPONSORS}

UNIVERSITY OF BRITISH COLUMBIA

UNIVERSITY OF SOUTHERN CALIFORNIA

CALIFORNIA INSTITUTE OF TECHNOLOGY

UNIVERSITY OF CALIFORNIA, BERKELEY

STANFORD RESEARCH INSTITUTE

UNIVERSITY OF CALIFORNIA, DAVIS

STANFORD UNIVERSITY

UNIVERSITY OF CALIFORNIA, LOS ANGELES

WASHINGTON STATE COLLEGE

UNIVERSITY OF CALIFORNIA, SANTA BARBARA

UNIVERSITY OF WASHINGTON

UNIVERSITY OF NEVADA

OREGON STATE COLLEGE

AMERICAN MATHEMATICAL SOCIETY

UNIVERSITY OF OREGON

HUGHES AIRCRAFT COMPANY

Mathematical papers intended for publication in the Pacific Journal of Mathematics should be typewritten (double spaced), and the author should keep a complete copy. Manuscripts may be sent to any of the editors. Manuscripts intended for the outgoing editors should be sent to their successors. All other communications to the editors should be addressed to the managing editor, E.G. Straus, at the University of California Los Angeles 24, California.

50 reprints of each article are furnished free of charge; additional copies may be obtained at cost in multiples of 50 .

The Pacific Journal of Mathematics is published quarterly, in March, June, September, and December. The price per volume (4 numbers) is $\$ 12.00$; single issues, $\$ 3.50$; back numbers (Volumes $1,2,3$ ) are available at $\$ 2.50$ per copy. Special price to individual faculty members of supporting institutions and to individual members of the American Mathematical Society: $\$ 4.00$ per volume; single issues, $\$ 1.25$.

Subscriptions, orders for back numbers, and changes of address should be sent to the publishers, University of California Press, Berkeley 4, California.

Printed at Ann Arbor, Michigan. Entered as second class matter at the Post Office, Berkeley, California.

* To be succeeded in 1955, by H.L. Royden, Stanford University, Stanford, California.

** To be succeeded in 1955, by E.G. Straus, University of California, Los Angeles 24, Calif.

UNIVERSITY OF CALIFORNIA PRESS - BERKELEY AND LOS ANGELES

COPYRIGHT 1954 BY PACIFIC JOURNAL OF MATHEMATICS 


\section{Pacific Journal of Mathematics}

\section{Vol. 4, No. $2 \quad$ June, 1954}

Henry Ludwig Alder, Generalizations of the Rogers-Ramanujan

identities ........................................ 161

E. M. Beelsey, Concerning total differentiability of functions of class $P$. . . 169

L. Carlitz, The number of solutions of some special equations in a finite

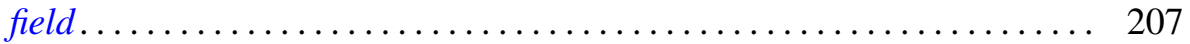

Marshall Hall, On a theorem of Jordan ............................ 219

J. D. Hill, Remarks on the Borel property..................... 227

Joseph Lehner, Note on the Schwarz triangle functions ............... 243

Arthur Eugene Livingston, A generalization of an inequality due to

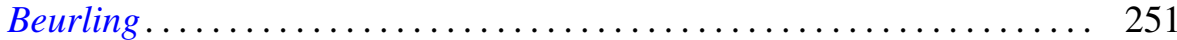

Edgar Reich, An inequality for subordinate analytic functions .......... 259

Dan Robert Scholz, Some minimum problems in the theory of functions ... . 275

J. C. Shepherdson, On two problems of Kurepa ................. 301

Abraham Wald, Congruent imbedding in F-metric spaces ............ 305

Gordon L. Walker, Fermat's theorem for algebras ............... 317 